\title{
Incidence, microbiology, and patient characteristics of skin and soft-tissue infections in a U.S. population: a retrospective population-based study
}

Gary Thomas Ray ${ }^{1 *}$, Jose Antonio Suaya ${ }^{2}$ and Roger Baxter ${ }^{3}$

\begin{abstract}
Background: Skin and soft tissue infections (SSTIs) are commonly occurring infections with wide-ranging clinical manifestations, from mild to life-threatening. There are few population-based studies of SSTIs in the period after the rapid increase in community-acquired methicillin-resistant Staphyloccus aureus (MRSA).

Methods: We used electronic databases to describe the incidence, microbiology, and patient characteristics of clinically-diagnosed skin and soft tissue infections (SSTIs) among members of a Northern California integrated health plan. We identified demographic risk factors associated with SSTIs and MRSA infection.

Results: During the three-year study period from 2009 to 2011, 376,262 individuals experienced 471,550 SSTI episodes, of which 23\% were cultured. Among cultured episodes, 54\% were pathogen-positive. Staphylococcus aureus (S. aureus) was isolated in $81 \%$ of pathogen-positive specimens, of which nearly half (46\%) were MRSA. The rate of clinically-diagnosed SSTIs in this population was 496 per 10,000 person-years. After adjusting for age group, gender, race/ethnicity and diabetes, Asians and Hispanics were at reduced risk of SSTIs compared to whites, while diabetics were at substantially higher risk compared to non-diabetics. There were strong age group by race/ ethnicity interactions, with African Americans aged 18 to $<50$ years being disproportionately at risk for SSTIs compared to persons in that age group belonging to other race/ethnicity groups. Compared to Whites, S. aureus isolates of African-Americans and Hispanics were more likely to be MRSA (Odds Ratio (OR): 1.79, Confidence Interval (Cl): 1.67 to 1.92 , and, OR: 1.24, Cl: 1.18 to 1.31 , respectively), while isolates from Asians were less likely to be MRSA (OR: 0.73 , Cl: 0.68 to 0.78$)$.
\end{abstract}

Conclusions: SSTIs represent a significant burden to the health care system. The majority of culture-positive SSTIs were caused by S. aureus, and almost half of the S. aureus SSTIs were methicillin-resistant. The reasons for African-Americans having a higher likelihood, and Asians a lower likelihood, for their S. aureus isolates to be methicillin-resistant, should be further investigated.

Keywords: Skin and soft-tissue infections, Methicillin-resistant staphylococcus aureus, Incidence, Epidemiology

\footnotetext{
*Correspondence: tom.ray@kp.org

${ }^{1}$ Division of Research, Kaiser Permanente Medical Care Program, Northern California Region, 2000 Broadway, Oakland, CA 94612, USA

Full list of author information is available at the end of the article
} 


\section{Background}

Skin and soft tissue infections (SSTIs) are common clinical conditions ranging from mild to life-threatening [1,2]. Because many episodes of SSTIs are not cultured, the most common causes of SSTIs in general remain uncertain, although Staphylococcus aureus (S. aureus) and betahemolytic streptococci (BHS) are often suggested as being the most important [3-6]. Among culture-confirmed SSTIs in the United States, the most common cause is $S$. aureus, although Pseudomonas aeruginosa, Enterococcus spp., Escherichia coli, and BHS have also been identified as important causes of some types of SSTIs [1,7-11].

Infections due to $S$. aureus present a significant health problem in the United States [12-14], and treatment of these infections has become more difficult in the last decade due to the emergence and rapid spread of methicillinresistant S. aureus (MRSA) [13-15]. Between 1995 and 2005 there was a dramatic increase in communityassociated MRSA (CA-MRSA), and this increase was most commonly associated with SSTIs [16-22]. Studies reported increasing numbers of emergency department visits and hospitalizations for SSTIs [23-25], contemporaneous with the emergence of CA-MRSA. A study from England reported a nearly two-fold increase in cellulitis-related hospitalizations in children from 1997 and 2006 [26]. However, there are some indications that the rate of MRSA infections has stabilized or declined in the last few years [27-30].

In a recently published report of trends in $S$. aureus among a Northern California population, we found that nearly $60 \%$ of culture-confirmed $S$. aureus infections were associated with a diagnosis of SSTI, and that the number of positive $S$. aureus cultures identified in this population was significantly higher in recent years (2006 to 2009) than in earlier years (1998-2001) [29]. However, because many SSTIs do not receive microbiological testing, analyses restricted to culture-confirmed infections do not fully address issues of disease burden. There are very few population-based estimates of the incidence of SSTI episodes requiring medical care, especially ones including years after the rapid rise in CA-MRSA, and which include non-cultured SSTIs and SSTIs treated in outpatient settings [26,31]. Given the paucity of large, population-based studies of SSTIs in all settings, with and without cultures, we conducted this study in a general membership of a large, integrated health plan, with the objective of determining the annual incidence of SSTIs, the rate and results of microbiological testing associated with SSTIs, and demographic and clinical risk factors for SSTIs, and SSTIs with culture-confirmed S. aureus and MRSA.

\section{Methods \\ Setting}

Kaiser Permanente of Northern California (KPNC) is a nonprofit, integrated health care delivery system providing care to over 3 million members. The member population reflects the general population in the Northern California region, although, as an insured population, it underrepresents persons with very low levels of education and income [32]. Clinical diagnostic and laboratory results data from hospital discharges and ambulatory settings, including emergency departments, are archived in electronic medical record and administrative databases. KPNC databases contain individual patient records and are readily linked using the patient's unique medical record number which remains with the patient for life. In this retrospective, observational, study, clinical decisions regarding diagnosing and testing reflect usual care by KPNC providers [29]. The study was approved by the KPNC Institutional Review Board.

\section{Definition of SSTI episodes}

Using electronic databases, we identified all clinic visits, Emergency Department visits, and hospital-based encounters occurring between January 1, 2009 and December 31, 2011, with a diagnosis (International Classification of Diseases, 9th Revision, Clinical Modification [ICD9-CM]) relating to SSTIs. We selected this threeyear period in order to reflect current practice patterns, to reflect a period when MRSA incidence appears to have stabilized [29], and because it was the most recent period for which we had complete diagnostic and laboratory data available for this population. For hospitalbased encounters, we only included SSTIs that were listed as the primary diagnosis, thus likely excluding hospital-onset cases - although some cases with a second co-primary diagnoses such as sepsis will also have been excluded. SSTIs were defined by ICD9-CM code as the following: Cellulitis and abscess, comprising abscess of anal and rectal region (566×), abscess of breast $(6751 \times, 6752 \times)$, cellulitis and abscess of finger and toe $(681 \times)$, other cellulitis and abscess $(682 \times)$, and pilonidal cyst with abscess (6850); Carbuncle and furuncle (680x); Impetigo (684); Other infections of skin and subcutaneous tissue $(686 \times)$; Folliculitis $(7048 \times)$; and Other skin and soft tissue infections, comprising erysipelas (035), other mastitis $(6752 \times)$, acute lymphadenitis (683), hydradenitis (70583), and necrotizing fasciitis (72886). These codes include most of those used by Edelsberg et al [25]. in their analysis of hospitalizations caused by SSTIs, plus erysipelas, abscess of breast, nonpurulent mastitis, folliculitis and hydradenitis. Because our focus was on acute, community-onset SSTIs, and not on nosocomial or chronic SSTIs, we did not include in these analyses chronic/decubitus ulcer, surgical site infection, post-operative wound infection, infection due to device, gangrene, or amputation stump infection.

SSTI episodes were defined as beginning on the date of the first SSTI diagnosis and ending with the last SSTI 
or complication diagnosis, not followed by another SSTI or complication diagnosis within 42 days. A six week period was considered short enough as to be unlikely to include multiple different episodes, but long enough to extend beyond the time that a patient might be asked to return for a follow-up visit. The start of an episode was defined solely by one of the diagnoses noted above. However, receipt of one or more complications diagnoses could prolong the episode. The following ICD-9-CM codes were considered potential SSTI complications: 038 (sepsis/septicemia), 04082 (toxic shock syndrome), 7280 (myositis), 730× (osteomyelitis), 7854 (gangrene), 78552 (septic shock), 7970× (bacteremia), 99590-99592 (systemic inflammatory response syndrome.) We retained only those episodes where the patient was a KPNC member at the start of the episode.

\section{Patient demographics and block group income}

Patient age and gender were extracted from KPNC membership databases. Although race/ethnicity is not systematically captured for all members, the race/ethnicity of a majority of patients (about 94\%) was identified via a search of electronic medical records, membership databases and other administrative databases. Patients were classified as Hispanic if their ethnicity was identified as "Hispanic" in any of these sources. For patients who did not have race/ethnicity recorded in administrative databases, we imputed race/ethnicity using the Bayesian Improved Surname and Geocoding algorithm, which uses census data and surname to impute the probabilities that the patient belonged to each of six different racial/ethnic groups [33].

Patient addresses were extracted from membership databases and were used to determine the patient's census block group. Using the American Community Survey 2006-2010 Summary File [34], we determined the median block group income for each patient, and classified their SSTIs based on the quintile of the block group median income. Persons whose address information did not map to a valid census block group were classified into a sixth category "unknown".

\section{Diabetes status as comorbidity of interest}

Because persons with diabetes are widely considered to be at increased risk of SSTIs [35-40], we classified SSTI episodes by the diabetes status of the patient. An SSTI episode was considered to be for a patient with diabetes if the patient was on the KPNC Diabetes Registry and was considered to have diabetes prior to the start of the episode. The KPNC Diabetes Registry was established in 1993 to monitor the quality of care and health outcomes for plan members with diabetes and is updated annually by identifying all plan members with diabetes from automated databases of pharmacy data, laboratory data, hospitalization records, and outpatient diagnoses [41-43].

\section{Microbiology of SSTIs}

Microbiology test results were extracted from KPNC's Laboratory Utilization and Reporting System. We retained for analysis all blood, body fluid, tissue, and other miscellaneous bacterial specimens (such as those taken from abscesses, pustules, boils, wounds, etc.) obtained from patients with SSTIs in the period from 7 days prior to the start of their SSTI episode to 7 days after the end of their SSTI episode. These tests were considered to have been performed to determine SSTI etiology. We excluded respiratory, cerebrospinal fluid and urine specimens. For those SSTI episodes where a microbiology test was ordered, we defined the "index specimen" as being the specimen from which the first clinically-relevant organism was isolated, or the first specimen obtained during the relevant time period if no organism was isolated. The isolate from the index specimen was defined as the "index isolate", and we considered this organism to be the cause of the infection. Episodes could be associated with more than one type of pathogen if multiple pathogens were identified from the index specimen.

Organisms were considered clinically-relevant pathogens only if the laboratory performed antibiotic susceptibility testing on the isolate, or if it was one of the following organisms which do not routinely receive antibiotic susceptibility testing: BHS, Streptococcus pneu moniae, Bacteroides spp., Fusobacterium spp., Haemophilus spp., Pasteurella spp., Peptococcus, Porphyromonas spp., Prevotella spp., Peptostreptococcus spp., and S. aureus. The following organisms were considered contaminants and were not counted as clinically-relevant pathogens: coagulase negative staphylococcus, Ochrobactrum, Corynebacterium, Micrococcus spp., Bacillus spp., gram positive cocci, gram positive rods, and streptococcus species other than BHS, S. pneumoniae, Streptococcus milleri, Streptococcus anginosus, Streptococcus constellatus, and Streptococcus intermedius. In addition, some uncommon organisms that could not be definitively speciated by the laboratory were also excluded.

\section{Crude incidence rates and predictors of clinically- diagnoses SSTIs}

The denominator used for calculating incidence rates was KPNC member years. We first identified all persons who were members of KPNC at any time between January 1, 2009 and December 31, 2011. KPNC membership systems track membership on a monthly basis and persons could enter and leave the health plan throughout this time. We summarized member months into strata by calendar year (2009, 2010 and 2011), age 
(in one-year increments), gender, race/ethnicity and diabetes status. SSTI episodes were also summarized by year, age group, gender, race/ethnicity and diabetes status. Persons could contribute more than one episode to the numerators.

Incidence rates were calculated by dividing the number of episodes in each stratum by the person-years in that stratum. For reporting, one-year age strata were summarized into five age groups (less than 5, 5- $<18$, $18-<50,50-<65$, and $65+$ years of age). Ninety-five percent confidence intervals for incidence rates were calculated using the following formulas:

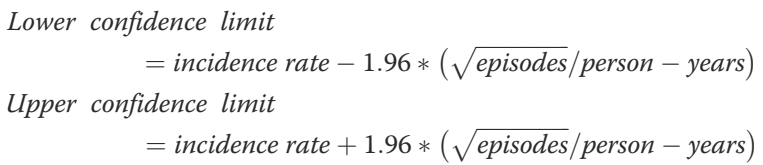

Rate ratios were estimated using a single multivariate negative binomial regression in which episodes from all years were included. Each record in the analytic dataset was one of the age, gender, race/ethnicity, and diabetes strata noted above. The dependent variable was the number of SSTI episodes for all patients in the stratum. Independent variables were gender, age group (less than $5,5-<18,18-<50,50-<65$, and $65+$ years of age), race/ ethnicity, and diabetes status. The log of person-years in each stratum was used as an offset term. In a sensitivity analysis, we ran the same model but included only the first SSTI per patient.

\section{Predictors of S. aureus and MRSA among cultured SSTIs}

We examined the relationship between demographic and clinical characteristics and the risk of S. aureus and MRSA. We created an analytic dataset that included all SSTI episodes from which a culture was obtained. Odds ratios were estimated using a multivariate logistic regression where the dependent variable was whether or not the culture was positive for $S$. aureus and the independent variables were gender, age (treated as a categorical variable with five levels: less than $5,5-<18,18-<50,50-$ $<65$, and $65+$ years of age), race/ethnicity, diabetes status, quintile of census block income, and the type of SSTI. Because some patients had more than one SSTI between 2009 and 2011, we used a generalized estimating equation approach with an exchangeable covariance structure to account for correlation among records for the same person. The resulting odds ratios represent the odds of testing positive for S. aureus given that microbiological testing was performed. A second model was run to identify the risk factors for testing positive for MRSA among those SSTI episodes that were positive for $S$. aureus. The dependent variable in this model was whether or not the SSTI was positive for MRSA and the independent variables were the same as in the first model. The resulting odds ratios represent the odds of testing positive for MRSA given that the SSTI was culture-confirmed S. aureus.

\section{Results}

Incidence and predictors of clinically-diagnosed SSTIs

During the three-year study period, 376,262 unique individuals experienced 471,550 SSTI episodes (Table 1). The majority of these SSTIs were coded as "cellulitis and abscess" (63\%), and the average age of patients was 41 years. The racial profile of SSTI patients was similar to that of the KPNC membership except that Asians were under-represented (12\% of SSTIs versus about $18 \%$ of KPNC members) and Whites were over-represented (54\% versus about $49 \%$ ). Twenty-three percent of SSTI episodes were cultured, and $12 \%$ of all episodes had a potentially clinically-relevant pathogen identified.

The rate of clinically-diagnosed SSTIs was 496 per 10,000 person-years, with the highest crude incidence rates being in persons 65 years of age and older, Native Americans, African-Americans, persons identified as Multiracial, and persons with diabetes (Table 2). After adjusting for patient demographics and diabetes (and including only main effects), children under 5 years of age had higher rates of SSTI than persons aged 65 years and older (Rate Ratio (RR): 1.21, Confidence Interval (CI): 1.17 to 1.26), while persons in other age groups had lower rates of SSTIs compared to persons aged 65 years and older. Asians (RR: 0.51, CI: 0.50 to 0.52), AfricanAmericans (RR: 0.94, CI: 0.92 to 0.96), and Hispanics (RR:0.81, CI: 0.80 to 0.83 all had lower rates of SSTIs than Whites. Persons with diabetes had nearly double the rate of SSTI compared to persons without diabetes (RR: $1.93, \mathrm{CI}: 1.90$ to 1.96 ). When we restricted the model to include only the first episode per individual, the $\mathrm{RR}$ associated with diabetes decreased from 1.98 to 1.69 (CI: 1.66 to 1.72 ), but all other results remained substantially the same. When diabetes was excluded from the main model (the one allowing multiple episodes per person), the results were substantially the same as when diabetes was included, with the exception that children under 5 years of age had a lower RR (RR: $0.901, \mathrm{CI}: 0.85$ to 0.95$)$ compared to persons aged 65 years and older, and Native Americans and persons identified as Multiracial join the other race/ethnicities in having lower risk of SSTI compared to Whites.

In a post-hoc analysis to investigate differences among the racial/ethnic groups in the relationship between age and the risk of SSTI, we re-ran the model but included an interaction term for race/ethnicity by age group. In this model, within each racial/ethnic group, the rates of SSTI in the younger age groups were compared to the rate in persons age 65 years and older (Table 3). This 
Table 1 Characteristics of clinically-diagnosed skin and soft tissue infection episodes, Kaiser Permanente of Northern California, 2009-2011 ${ }^{\text {a }}$

\begin{tabular}{|c|c|}
\hline All episodes & $471,550(100)$ \\
\hline \multicolumn{2}{|l|}{ Type of SSTI } \\
\hline Carbuncle and furuncle & $24,238(5)$ \\
\hline Impetigo & $37,075(8)$ \\
\hline Other infections of the skin & $31,870(7)$ \\
\hline Folliculitis & $69,000(15)$ \\
\hline Other SSTI & $11,331(2)$ \\
\hline Cellulitis and abscess & $298,036(63)$ \\
\hline \multicolumn{2}{|l|}{ Gender } \\
\hline Female & $249,844(53)$ \\
\hline Male & $221,706(47)$ \\
\hline \multicolumn{2}{|l|}{ Age in years } \\
\hline Under 5 & $32,384(7)$ \\
\hline $5-<18$ & $73,779(16)$ \\
\hline $18-<50$ & $185,103(39)$ \\
\hline $50-<65$ & $97,277(21)$ \\
\hline $65+$ & $83,007(18)$ \\
\hline Mean age (std) & $40.82(24)$ \\
\hline \multicolumn{2}{|l|}{ Race/ethinicity } \\
\hline Asian & $55,595(12)$ \\
\hline African-American & $43,407(9)$ \\
\hline Hispanic & $96,626(20)$ \\
\hline Native American & $2,967(1)$ \\
\hline Multiracial & $18,449(4)$ \\
\hline White & $254,507(54)$ \\
\hline Microbiology test performed ${ }^{b}$ & $108,243(23)$ \\
\hline Any pathogen identified by microbiology test & $58,794(12)$ \\
\hline \multicolumn{2}{|c|}{$\begin{array}{l}\text { a Episodes were defined as beginning on the date of the first skin and soft } \\
\text { tissue infection (SSTI) diagnosis and ending with the last SSTI or SSTl-related } \\
\text { complication diagnosis, not followed by another SSTI or SSTI complication } \\
\text { diagnosis within } 42 \text { days. Duration of health services use was calculated as the } \\
\text { number of days from the start of the episode to the end of the episode. } \\
\text { Values in columns are number of episodes and percent of all episodes, unless } \\
\text { otherwise indicated. } \\
\text { b Microbiology tests included in analyses were those performed on blood, } \\
\text { tissue, body fluid or other miscellaneous bacterial specimens (such as those } \\
\text { taken from abscesses, pustules, boils, etc.) obtained from the patient within } \\
7 \text { days prior to the beginning of the SSTI episode to } 7 \text { days after the end of } \\
\text { the episode. Respiratory, cerebrospinal fluid and urine specimens were } \\
\text { excluded. These microbiology tests were considered to have been performed } \\
\text { to determine SSTI etiology. A minority of episodes received such testing. }\end{array}$} \\
\hline
\end{tabular}

model indicated that children less than 5 years of age had a significantly higher rate of SSTI compared to persons 65 years of age and older in Asians (RR: 1.86, CI: 1.74 to 2.00), African-Americans (RR: 1.51, CI 1.40 to 1.62), and Hispanics (RR: 1.22, CI: 1.14 to 1.30), but not in Native Americans, persons classified as multiracial, or Whites. Also notable was that African-Americans aged 18 to $<50$ and 50 to $<65$ had substantially higher rates of
SSTI compared to African-Americans 65 years of age and older (RR: 1.59, CI: 1.52 to 1.66, and, RR: 1.19, CI: 1.14 to 1.25 , respectively). When the same model was rerun, but parameterized in such a way that within each age group the rate in Whites was the reference group, Asians were found, at every age, to have lower rates of SSTI than Whites of the same age, and Hispanics were found to have lower rates of SSTI at every age group except children under 5 years, compared to Whites of the same age group (not shown). African Americans aged 18 to $<50$ had a higher rate of SSTI (RR: 1.27, CI: 1.23 to 1.31) compared to whites of the same age, but at other ages had similar, or lower rates, than Whites.

\section{Rates and microbiology of SSTls with microbiologic testing.}

Among episodes with a culture, $54 \%$ had a pathogen identified (Table 4). S. aureus was by far the most common pathogen, isolated in $81 \%$ of pathogen-positive index specimens. Among S. aureus isolates, $46 \%$ were MRSA (37\% of all pathogen-positive index specimens). Other important pathogens were BHS (10\% of pathogen-positive index specimens) and gram negative bacteria (14\%). Multiple pathogens were identified in $6 \%$ of index specimens with a pathogen.

\section{Predictors of S. aureus and MRSA}

Among SSTI episodes with a culture, there was a consistent trend of younger persons being more likely to test positive for $S$. aureus (Table 5). Episodes in children under 5 years of age had 3.89 (CI: 3.64 to 4.14) times the odds of being $S$. aureus compared to episodes in persons 65 years and older. Hispanics were somewhat more likely to test positive for $S$. aureus than were whites, and persons living in less affluent census blocks were more likely to test positive for $S$. aureus than persons in more affluent census blocks. Carbuncle/furuncle and cellulitis and abscess were more likely to be culture-positive for $S$. aureus than were other types of SSTIs.

Among SSTI episodes with a positive S. aureus culture, isolates from females were slightly more likely to be MRSA (Odds Ratio (OR): 1.04, CI: 1.00 to 1.09, compared to males). Compared to Whites, isolates from African-Americans were more likely to be MRSA (OR: 1.79, CI: 1.67 to 1.92 ) as were those of Hispanics (OR: 1.24, CI: 1.18 to 1.31). Isolates from Asians, on the other hand, were substantially less likely to be MRSA than those of whites (OR: 0.73, CI: 0.68 to 0.78 ) or other $\mathrm{racial} / \mathrm{ethnic}$ groups. Isolates from persons living in less affluent census blocks were more likely to be MRSA compared to isolates from persons living in more affluent census blocks. Isolates from diabetics were less likely to be MRSA than isolates from non-diabetics (OR: 0.75, CI: 0.71 to 0.80 ), and carbuncle/furuncle and cellulitis 
Table 2 Incidence rates of clinically-diagnosed skin and soft tissue infection episodes and adjusted relative rate ratios: model with main effects only

\begin{tabular}{|c|c|c|}
\hline $\begin{array}{c}\text { Patient } \\
\text { characteristic }\end{array}$ & $\begin{array}{l}\text { Episodes per } 10,000 \\
\text { person-years }(95 \% \mathrm{Cl})\end{array}$ & $\begin{array}{l}\text { Adjusted relative } \\
\text { rate ratio }(95 \% \mathrm{Cl})^{\text {a }}\end{array}$ \\
\hline All & 496 (494-497) & \\
\hline \multicolumn{3}{|l|}{ Gender } \\
\hline Female & $506(504-508)$ & $1.05(1.04,1.07)$ \\
\hline Male & $485(483-487)$ & ref \\
\hline \multicolumn{3}{|l|}{ Age (years) } \\
\hline Under 5 & $579(573-585)$ & $1.21(1.17,1.26)$ \\
\hline $5-<18$ & $440(437-443)$ & $0.88(0.85,0.90)$ \\
\hline $18-<50$ & $462(460-464)$ & $0.98(0.96,1.00)$ \\
\hline $50-<65$ & $488(485-491)$ & $0.87(0.85,0.89)$ \\
\hline $65+$ & $652(648-657)$ & ref \\
\hline \multicolumn{3}{|l|}{ Race/Ethnicity } \\
\hline Asian & $320(317-322)$ & $0.51(0.50,0.52)$ \\
\hline African-American & $589(584-595)$ & $0.94(0.92,0.96)$ \\
\hline Hispanic & $474(471-477)$ & $0.81(0.80,0.83)$ \\
\hline Native American & $630(608-653)$ & $1.03(0.99,1.07)$ \\
\hline Multiracial & $600(591-609)$ & $0.98(0.96,1.00)$ \\
\hline White & $548(546-550)$ & ref \\
\hline \multicolumn{3}{|l|}{ Diabetes } \\
\hline Yes & 928 (921-936) & $1.93(1.90,1.96)$ \\
\hline No & $462(461-464)$ & \\
\hline
\end{tabular}

Kaiser Permanente of Northern California, 2009 to 2011.

${ }^{a}$ Rate ratios were derived from a single multivariate negative binomial model. The entire KPNC membership for years 2009-2011 were summarized into strata by gender, age, race, and diabetes status. Each record in the analytic dataset was one of these strata. The dependent variable was the number of SSTI episodes for all members in the strata. Independent variables were gender, age, race and diabetes status. The log of member years in each strata was used as an offset term. The model presented here includes only main effects, and thus represents averages across groups. Ref $=$ reference group; $\mathrm{Cl}=95 \%$ confidence interval.

and abscess isolates were more likely to be MRSA than were isolates from other types of SSTI (OR: 1.22, CI: 1.14 to 1.30$)$.

\section{Discussion}

Over the three-year period from 2009 to 2011, we found that the incidence of clinically-diagnosed SSTIs in this population was nearly 500 episodes per 10,000 personyears. By contrast, this rate is more than double the incidence of clinically-diagnosed pneumonia (approximately 190 per 10,000 ) in this population (unpublished data), although pneumonia is more likely to result in hospitalization.

In one of the few U.S. population-based studies of the incidence of community-onset SSTIs published in the last decade, Simonsen et al., using 1997 to 2002 data from a Western U.S. medical insurance claims database, reported the incidence rate of cellulitis and abscess in persons less than 65 years of age to be 241 per 10,000 person years [31]. The corresponding rate in our population for 2009-2011 (when restricting the analysis to cellulitis and abscess in persons under 65 years of age) was essentially the same (about 244 per 10,000 person-years).

In the multivariate model adjusting for gender, age group, race/ethnicity, and diabetes status, being under 5 years of age, and having diabetes were the two largest risk factors for being diagnosed with an SSTI. The increased risk of SSTIs among diabetics may, in part, be related to increased opportunities to get diagnosed, variations in care-seeking behavior, and other comorbidities, rather than directly related to diabetes [44]. However, one study that adjusted for some of these factors also found that diabetics were at increased risk of skin infections [35]. White race was also a risk factor for being diagnosed with SSTI. In a post-hoc analysis, we found that the relationship of age to the rate of clinically-diagnosed SSTI was different depending on race/ethnicity. Notably, unlike whites, the highest rate of SSTI in Asians, Hispanics, and Native Americans was in the youngest age group, rather than the elderly. Among AfricanAmericans, although the youngest age group also had a higher rate of SSTI than the elderly, persons $18-<$ 50 years of age had the highest rate of SSTI. That the effect of age group was significantly different by race/ ethnicity, reminds us that models that include only main effects may mask important differences.

Because of inability to determine microbiologic etiology of many SSTIs, and potential bias with respect to which SSTIs get cultured, it is difficult to infer the true underlying proportion of SSTIs due to given pathogens. The sample of SSTIs that get cultured are not representative of all SSTIs, especially given that many SSTIs are typically not culturable (e.g., cellulitis without abscess). In our setting, $23 \%$ of SSTI episodes were cultured, and a potentially clinically-relevant pathogen was isolated in $54 \%$ of those episodes. Over $80 \%$ of pathogen-positive specimens were $S$. aureus while only $10 \%$ were BHS. However, studies indicate that non-culturable cellulitis may be more likely to be caused by BHS than S. aureus [6], so BHS may represent a more important cause of SSTIs than the results of cultures indicate.

Among S. aureus isolates, we found that $46 \%$ were MRSA. Prior studies have shown that $S$. aureus is the leading cause of cultured SSTIs [7-11,45-50], and that the percent of these that were MRSA increased during the early 2000's [7,51,52]. However, most of these studies only included hospitalized cases [7-11,51] or were for special populations (i.e., children [51] and the uninsured $[49,50])$. In a 2004 study of specimens $(n=422)$ taken from ambulatory patients with SSTIs $(n=422)$, Moran et al. reported that $S$. aureus was isolated in $76 \%$ of the specimens, and $78 \%$ of these were MRSA [47]. MRSA 
Table 3 Incidence rates of clinically-diagnosed skin and soft tissue infection episodes and adjusted relative rate ratios: model including race*age interaction

\begin{tabular}{lll}
\hline $\begin{array}{c}\text { Patient } \\
\text { characteristic }\end{array}$ & $\begin{array}{l}\text { Race }{ }^{*} \text { age } \\
\text { interaction }\end{array}$ & $\begin{array}{c}\text { Adjusted relative } \\
\text { rate ratio }(95 \% \mathrm{Cl})\end{array}$ \\
\hline All & & \\
Gender & &
\end{tabular}

Gender

Female

$1.05(1.04,1.07)$

Male

Diabetes

Yes

$1.95(1.93,1.98)$

No

Race/ethnicity

Asian

$0.43(0.41,0.44)$

African-American

$0.64(0.61,0.67)$

Hispanic

$0.73(0.71,0.75)$

Native American

$0.94(0.85,1.04)$

Multiracial

$0.96(0.92,1.00)$

White

Race/ethnicity * Age

Asian

Under 5

$1.86(1.74,2.00)$

$5-<18$

$18-<50$

$50-<65$

$65+$

African-American

Under 5

$5-<18$

$18-<50$

$50-<65$

$65+$

Hispanic

Under 5

$5-<18$

$18-<50$

$50-<65$

$65+$

Native American

Under 5

$5-<18$

$18-<50$

50- $<65$

$65+$

Multiracial

Under 5

$5-<18$

$18-<50$

$50-<65$

$65+$

White

Under 5

5- $<18$
Table 3 Incidence rates of clinically-diagnosed skin and soft tissue infection episodes and adjusted relative rate ratios: model including race*age interaction (Continued)

$\begin{array}{rr}18-<50 & 0.80(0.78,0.82) \\ 50-<65 & 0.78(0.76,0.81) \\ 65+ & \text { REF }\end{array}$

Kaiser Permanente of Northern California, 2009 to 2011

${ }^{a}$ Rate ratios were derived from a single multivariate negative binomial model. The entire KPNC membership for years 2009-2011 were summarized into strata by gender, age, race, and diabetes status. Each record in the analytic dataset was one of these strata. The dependent variable was the number of SSTI episodes for all members in the strata. Independent variables were gender, race, race*age, and diabetes status. The log of member years in each strata was used as an offset term. Ref = reference group; $\mathrm{Cl}=95 \%$ confidence interval.

Table 4 Skin and soft tissue infections with microbiologic testing, Kaiser Permanente of Northern California, 2009-2011

\begin{tabular}{lr}
\multicolumn{1}{c}{$\begin{array}{c}\text { SSTI episodes with } \\
\text { microbiologic testing }\end{array}$} & $\mathbf{1 0 8 , 2 4 3 ( \mathbf { 1 0 0 } )}$ \\
\hline Any pathogen identified by micriobiology test & $58,794(54)$ \\
Specimen type & \\
Blood & $14,761(14)$ \\
Other & $93,482(86)$
\end{tabular}

Microbiology results: Among episodes with culture-confirmed pathogen ${ }^{c}$

$\begin{array}{lr}\text { MRSA } & 21,890(37) \\ \text { MSSA } & 25,628(44) \\ \text { BHS } & 5,729(10) \\ \text { Other streptococci } & 72(<1) \\ \text { Other gram positive bacteria } & 923(2) \\ \text { Gram negative bacteria } & 7,955(14) \\ \text { Anaerobic bacteria } & 101(<1)\end{array}$

${ }^{a}$ Only SSTIs with a microbiology test are included in this table. Only tests performed on specimens obtained in the period from 7 days prior to the start of the SSTI episode to 7 days after the end of the SSTI episode were included. These tests were considered to have been performed to determine SSTI etiology. MRSA = methicillin-resistant $S$. aureus; MSSA = methicillin-sensitive $S$. aureus; BHS = beta-hemolytic streptococcus. Data are number (\%) of cultured SSTI episodes, unless otherwise indicated.

${ }^{\mathrm{b}}$ Specimen type was the first positive specimen during the episode, or, if no specimens were positive, the first specimen. "Other" specimens include tissue, body fluid, and other miscellaneous bacterial specimens such as those taken from abscesses, pustules, boils, etc. Respiratory, CSF and urine cultures were excluded.

${ }^{c}$ Denominator for percents is the number of episodes with any positive pathogen. Pathogen results are not mutually-exclusive. Over the study period $6 \%$ of first positive specimens were positive for multiple organisms. "Other streptococci" comprises S. pneumoniae, S. milleri, S. anginosus, S. constellatus, and S. intermedius. The following organisms were considered contaminants and not included: coagulase negative staphylococcus, ochrobactrum, corynebacterium, micrococcus spp., bacillus spp., gram positive cocci, gram positive rods, and streptococcus species other than BHS, S. pneumoniae, and "other streptococci" as defined above. "BHS" comprises streptococci with Lancefield groups A, B, C and G. 
Table 5 Risk factors for S. aureus and methicillin-resistant S. aureus skin and soft tissue infection episodes, Kaiser Permanente of Northern California, 2009-2011 ${ }^{\mathrm{a}}$

\begin{tabular}{|c|c|c|}
\hline \multirow[b]{3}{*}{ Characteristic } & \multicolumn{2}{|c|}{ Adjusted odds ratio $(95 \% \mathrm{Cl})^{\mathrm{b}}$} \\
\hline & Among all episodes with a culture $(n=108243)^{c}$ & Among episodes positive for $S$. aureus $(n=47518)^{d}$ \\
\hline & Odds of S. aureus vs. not S. aureus & Odds of MRSA vs. MSSA \\
\hline \multicolumn{3}{|l|}{ Gender } \\
\hline Female & $0.86(0.84,0.88)$ & $1.04(1.00,1.09)$ \\
\hline Male & ref & ref \\
\hline \multicolumn{3}{|l|}{ Age (years) } \\
\hline Under 5 & $3.89(3.64,4.14)$ & $1.28(1.17,1.40)$ \\
\hline $5-<18$ & $2.64(2.52,2.78)$ & $0.79(0.73,0.85)$ \\
\hline $18-<50$ & $1.91(1.83,1.98)$ & $1.11(1.04,1.18)$ \\
\hline $50-<65$ & $1.40(1.34,1.46)$ & $1.03(0.96,1.10)$ \\
\hline $65+$ & ref & ref \\
\hline \multicolumn{3}{|l|}{ Race/Ethnicity } \\
\hline Asian & $1.02(0.98,1.06)$ & $0.73(0.68,0.78)$ \\
\hline African-American & $1.02(0.98,1.07)$ & $1.79(1.67,1.92)$ \\
\hline Hispanic & $1.05(1.01,1.08)$ & $1.24(1.18,1.31)$ \\
\hline Native American & $1.11(0.95,1.30)$ & $1.16(0.92,1.46)$ \\
\hline Multiracial & $0.95(0.89,1.02)$ & $1.01(0.91,1.13)$ \\
\hline White & ref & ref \\
\hline \multicolumn{3}{|l|}{ Diabetes status } \\
\hline Diabetes & $0.93(0.90,0.97)$ & $0.75(0.71,0.80)$ \\
\hline No diabetes & ref & ref \\
\hline \multicolumn{3}{|l|}{ Census Block Income Quintile } \\
\hline Unknown & $1.16(1.10,1.23)$ & $1.27(1.17,1.38)$ \\
\hline 1st (lowest income) & $1.17(1.12,1.22)$ & $1.42(1.33,1.51)$ \\
\hline 2nd & $1.13(1.09,1.18)$ & $1.25(1.17,1.34)$ \\
\hline $3 r d$ & $1.08(1.03,1.12)$ & $1.15(1.08,1.22)$ \\
\hline 4th & $1.02(0.98,1.07)$ & $1.12(1.05,1.20)$ \\
\hline 5th (highest income) & ref & ref \\
\hline \multicolumn{3}{|l|}{ Type of SSTI } \\
\hline Carbuncle and furuncle & $1.33(1.26,1.40)$ & $1.22(1.14,1.30)$ \\
\hline Impetigo & $1.03(0.97,1.09)$ & $0.16(0.14,0.18)$ \\
\hline Other infections of the skin & $1.06(1.00,1.11)$ & $0.55(0.51,0.59)$ \\
\hline Folliculitis & $0.87(0.83,0.91)$ & $0.50(0.46,0.53)$ \\
\hline Other SSTI & $0.48(0.42,0.53)$ & $0.68(0.56,0.82)$ \\
\hline Cellulitis and abscess & ref & ref \\
\hline
\end{tabular}

${ }^{\text {a }} \mathrm{Cl}=95 \%$ confidence interval; $\mathrm{MSSA}=$ methicillin-sensitive $S$. aureus; $\mathrm{MRSA}=$ methicillin-resistant $\mathrm{S}$. aureus; ref = reference group for other odds ratios within characteristic.

${ }^{b}$ Odds ratios estimated using multivariate logistic regression. A separate model was run for each column in the table. For both models the independent variables were gender, age, race/ethnicity, diabetes status, income quintile based on census block, and type of SSTI.

c The analytic dataset had one record per SSTI episode with a microbiologic test, and the dependent variable was whether or not the test was positive for $S$. aureus. Specimens may have been positive for other organisms or no organism may have been identified. Episodes without a microbiologic test were not included in the model.

${ }^{d}$ The analytic dataset had a record for each SSTI episode that tested positive for S. aureus. The dependent variable was whether or not the isolate was methicillin-resistant. 
may have been more prevalent in the Moran et al. population compared to KPNC in part because of the larger percent of African-Americans and Hispanics in that population, which, in the KPNC population, were more likely to have $S$. aureus SSTIs that were MRSA than Whites or Asians. In a study of San Francisco Bay Area outpatients $(\mathrm{n}=529)$ presenting with purulent or fluidproducing SSTIs during 2006-2007, Weiss et al. found that, among those with microbiologic testing, $22 \%$ of specimens were positive for MRSA and 30\% for methicillinsensitive S. aureus (MSSA) [45]. These compare to 20\% (MRSA) and 24\% (MSSA) in our study, when the denominator was all SSTIs with microbiologic testing.

While diabetes was associated with higher risk of SSTIs (and higher absolute rates of MRSA), it was not associated with an increased risk of MRSA infection compared to MSSA - in fact, it was associated with a decreased risk. This finding is consistent with a recent study of hospitalized patients with complicated SSTIs and a positive blood or skin culture, which found that not having evidence of diabetes corresponded to an increased likelihood of the culture being MRSA [53]. In part, these findings in our population may be related to a higher propensity of providers to order cultures for diabetics. We found that $31 \%$ of SSTI episodes for diabetics were cultured, while only $22 \%$ of SSTI episodes for non-diabetics were cultured, and that the cultures obtained from diabetics were more likely to be blood than were the cultures from non-diabetics (24\% vs. $11 \%)$. Thus, for diabetics, providers may have disproportionately ordered cultures for types of SSTIs that were less likely to MRSA. These findings related to diabetics should be further explored.

Consistent with a number of prior studies [12,14, 27,54-56], we found that, among persons with S. aureus infections, African-Americans and persons living in lower-income census blocks were at substantially increased risk of their $S$. aureus being methicillinresistant. We also found that Asians were at substantially lower risk of being diagnosed with an SSTI, and that their SSTI-related S. aureus isolates were substantially less likely to be methicillin-resistant than those of other racial/ethnic groups. No US population-based study has, to our knowledge, previously reported on rates of SSTI and likelihood of $S$. aureus being methicillin-resistant in persons of Asian race vis-à-vis persons of other racial/ethnic groups. However, Liu et al. reported that, among San Francisco residents, Asian/Pacific Islanders had the lowest rates of community-onset and hospital-onset MRSA disease, much of which was likely related to SSTI [54]. Our findings with respect to Asians are novel and should be confirmed in other populations.

\section{Limitations}

Our selection criteria explicitly excluded SSTIs diagnoses that we thought likely be represent nosocomial or chronic infections, and thus our incidence rates and microbiology results do not reflect inclusion of those types of infections. In addition, our findings reflect the routine practice of providers in this health plan with respect to diagnosing and microbiologic testing, and these practices may differ from those of other settings. The differences we found in risk of SSTIs among the different gender, race/ethnicity, and age groups, may to some extent reflect differences in the propensity of persons in these groups to seek treatment. As an observational study, our analysis of risk factors could be affected by unmeasured confounders. We did not include, for example, nursing home status, family size, injection drug use, or medical conditions other than diabetes. We included diabetes as a risk factor due to the high prevalence of the condition, and because prior literature suggests its relationship to increased risk of SSTI [35-37,39,40]. However, other conditions - in particular, immunocompromising conditions such as HIV - might also be associated with increased risk of SSTIs. In this study we did not assess severity or health services utilization. Therefore, higher risk of clinically-diagnosed SSTIs does not necessarily imply more severity or greater overall cost of care. Cultures were included based on their temporal proximity to a patient's SSTI diagnosis. It is possible that some patients may have multiple infections, and that the pathogen we associated with the SSTI infection may not have been the cause of that infection.

\section{Conclusions}

SSTIs represent a significant burden to the health care system. The majority of culture-positive SSTIs were caused by S. aureus, and half of the S. aureus SSTIs were methicillin-resistant. After adjusting for demographic variables and diabetes status, diabetics, persons in the lower economic strata, and children under 5 years of age were at particular risk of SSTI, while Asians were at lower risk. Our findings that the relationship of age to the rate of SSTIs differed considerably by race/ethnicity warrants further investigation.

\section{Abbreviations}

SSTI: Skin and soft-tissue infection; S. aureus: Staphylococcus aureus; BHS: Beta-hemolytic streptococci; MRSA: Methicillin-resistant Staphylococcus aureus; MSSA: Methicillin-sensitive Staphylococcus aureus; KPNC: Kaiser Permanente of Northern California; CA-MRSA: Community-associated methicillin-resistant Staphylococcus aureus; ICD9-CM: international classification of disease, 9th revision, clinical modification; OR: Odds ratio; $\mathrm{Cl}$ : Confidence Interval

\section{Competing interests}

G. Thomas Ray has received research support from GlaxoSmithKline, Pfizer, Merck and Purdue Pharma L.P. Roger Baxter has received research funding from GlaxoSmithKline, Pfizer, Merck, Sanofi Pasteur and Novartis. Jose A. 
Suaya is an employee of GlaxoSmithKline and received restricted shares of company stock.

\section{Authors' contributions}

GTR contributed to the design of the study, made substantial contributions to the data acquisition, data analysis, and interpretation of data, and was primarily responsible for drafting the manuscript. JAS contributed to the design of the study, made substantial contributions to the interpretation of data, and helped to draft the manuscript and revise it for important intellectual content. RB conceived the study, contributed to the design of the study, made substantial contributions to the interpretation of data, and helped to draft the manuscript and revise it for important intellectual content. All authors read and approved the final manuscript. The authors thank Heather Santiago (GlaxoSmithKline Vaccines) for managing the manuscript.

\section{Acknowledgements}

This study was funded by a research grant from GlaxoSmithKline Biologicals $\mathrm{SA}$. The sponsor had the opportunity to review and comment on the manuscript.

\section{Author details}

${ }^{1}$ Division of Research, Kaiser Permanente Medical Care Program, Northern California Region, 2000 Broadway, Oakland, CA 94612, USA. ${ }^{2}$ Health Outcomes, North America Vaccine Development, GlaxoSmithKline Vaccines, 200 N16th Street, Philadelphia, PA 19102, USA. ${ }^{3}$ Kaiser Permanente Vaccine Study Center and The Permanente Medical Group, 1 Kaiser Plaza, Oakland, CA 94612, USA.

Received: 11 January 2013 Accepted: 23 May 2013

Published: 30 May 2013

\section{Reference}

1. Ki V, Rotstein C: Bacterial skin and soft tissue infections in adults: A review of their epidemiology, pathogenesis, diagnosis, treatment and site of care. Can J Infect Dis Med Microbiol 2008, 19:173-184.

2. Dryden M: Complicated skin and soft tissue infections caused by methicillin-resistant Staphylococcus aureus: epidemiology, risk factors, and presentation. Surg Infect (LarChmt) 2008, 9(Suppl 1):s3-10.

3. Eron $\amalg$, Lipsky BA, Low DE, Nathwani D, Tice AD, Volturo GA: Managing skin and soft tissue infections: expert panel recommendations on key decision points. J Antimicrob Chemother 2003, 52(Suppl 1):i3-i17.

4. Dryden MS: Skin and soft tissue infection: microbiology and epidemiology. Int J Antimicrob Agents 2009, 34(Suppl 1):S2-S7.

5. Vinh DC, Embil JM: Rapidly progressive soft tissue infections. Lancet Infect Dis 2005, 5:501-513.

6. Jeng A, Beheshti M, Li J, Nathan R: The role of beta-hemolytic streptococci in causing diffuse, nonculturable cellulitis: a prospective investigation. Medicine (Baltimore) 2010, 89:217-226

7. Moet GJ, Jones RN, Biedenbach DJ, Stilwell MG, Fritsche TR: Contemporary causes of skin and soft tissue infections in North America, Latin America, and Europe: report from the SENTRY Antimicrobial Surveillance Program (1998-2004). Diagn Microbiol Infect Dis 2007, 57:7-13.

8. Zilberberg MD, Shorr AF, Micek ST, Hoban AP, Pham V, Doherty JA, Ramsey AM, Kollef $\mathrm{MH}$ : Epidemiology and outcomes of hospitalizations with complicated skin and skin-structure infections: implications of healthcare-associated infection risk factors. Infect Control Hosp Epidemiol 2009, 30:1203-1210.

9. Rennie RP, Jones RN, Mutnick AH: Occurrence and antimicrobial susceptibility patterns of pathogens isolated from skin and soft tissue infections: report from the SENTRY Antimicrobial Surveillance Program (United States and Canada, 2000). Diagn Microbiol Infect Dis 2003, 45:287-293.

10. Jenkins TC, Sabel AL, Sarcone EE, Price CS, Mehler PS, Burman WJ: Skin and soft-tissue infections requiring hospitalization at an academic medical center: opportunities for antimicrobial stewardship. Clin Infect Dis 2010, 51:895-903.

11. Lipsky BA, Weigelt JA, Gupta V, Killian A, Peng MM: Skin, soft tissue, bone, and joint infections in hospitalized patients: epidemiology and microbiological, clinical, and economic outcomes. Infect Control Hosp Epidemiol 2007, 28:1290-1298.
12. Fridkin SK, Hageman JC, Morrison M, Sanza LT, Como-Sabetti K, Jernigan JA, Harriman K, Harrison LH, Lynfield R, Farley MM: Methicillin-resistant Staphylococcus aureus disease in three communities. N Engl J Med 2005, 352:1436-1444.

13. Klein E, Smith DL, Laxminarayan R: Hospitalizations and deaths caused by methicillin-resistant Staphylococcus aureus, United States, 1999-2005. Emerg Infect Dis 2007, 13:1840-1846.

14. Klevens RM, Morrison MA, Nadle J, Petit S, Gershman K, Ray S, Harrison LH, Lynfield R, Dumyati G, Townes JM, et al: Invasive methicillin-resistant Staphylococcus aureus infections in the United States. JAMA 2007, 298:1763-1771.

15. Shorr AF: Epidemiology and economic impact of meticillin-resistant Staphylococcus aureus: review and analysis of the literature. Pharmaco Economics 2007, 25:751-768.

16. Dietrich DW, Auld DB, Mermel LA: Community-acquired methicillinresistant Staphylococcus aureus in southern New England children. Pediatrics 2004, 113:e347-e352.

17. Morin CA, Hadler JL: Population-based incidence and characteristics of community-onset Staphylococcus aureus infections with bacteremia in 4 metropolitan Connecticut areas, 1998. J Infect Dis 2001, 184:1029-1034.

18. Miller LG, Kaplan SL: Staphylococcus aureus: a community pathogen. Infect Dis Clin North Am 2009, 23:35-52.

19. Crum NF, Lee RU, Thornton SA, Stine OC, Wallace MR, Barrozo C, Keefer-Norris A, Judd S, Russell KL: Fifteen-year study of the changing epidemiology of methicillin-resistant Staphylococcus aureus. Am J Med 2006, 119:943-951.

20. Farley JE: Epidemiology, clinical manifestations, and treatment options for skin and soft tissue infection caused by community-acquired methicillinresistant Staphylococcus aureus. J Am Acad Nurse Pract 2008, 20:85-92.

21. King MD, Humphrey BJ, Wang YF, Kourbatova EV, Ray SM, Blumberg HM: Emergence of community-acquired methicillin-resistant Staphylococcus aureus USA 300 clone as the predominant cause of skin and soft-tissue infections. Ann Intern Med 2006, 144:309-317.

22. Adam HJ, Allen VG, Currie A, McGeer AJ, Simor AE, Richardson SE, Louie L, Willey B, Rutledge T, Lee J, et al: Community-associated methicillinresistant Staphylococcus aureus: prevalence in skin and soft tissue infections at emergency departments in the Greater Toronto Area and associated risk factors. CJEM 2009, 11:439-446.

23. Pallin DJ, Egan DJ, Pelletier AJ, Espinola JA, Hooper DC, Camargo CA Jr: Increased US emergency department visits for skin and soft tissue infections, and changes in antibiotic choices, during the emergence of community-associated methicillin-resistant Staphylococcus aureus. Ann Emerg Med 2008, 51:291-298.

24. McCaig LF, McDonald LC, Mandal S, Jernigan DB: Staphylococcus aureus-associated skin and soft tissue infections in ambulatory care. Emerg Infect Dis 2006, 12:1715-1723.

25. Edelsberg J, Taneja C, Zervos M, Haque N, Moore C, Reyes K, Spalding J, Jiang J, Oster G: Trends in US hospital admissions for skin and soft tissue infections. Emerg Infect Dis 2009, 15:1516-1518.

26. Saxena S, Thompson P, Birger R, Bottle A, Spyridis N, Wong I, Johnson AP, Gilbert R, Sharland M: Increasing skin infections and Staphylococcus aureus complications in children, England, 1997-2006. Emerg Infect Dis 2010, 16:530-533.

27. Kallen AJ, Mu Y, Bulens S, Reingold A, Petit S, Gershman K, Ray SM, Harrison LH, Lynfield R, Dumyati G, et al: Health care-associated invasive MRSA infections, 2005-2008. JAMA 2010, 304:641-648.

28. Diamantis ML, Ortega-Loayza AG, Morrell DS: Update on the characterization of Staphylococcus aureus skin infections in a pediatric dermatology tertiary health care outpatient facility: antibiotic susceptibility patterns and decreased methicillin resistance. J Am Acad Dermatol 2011, 64:440-441.

29. Ray GT, Suaya JA, Baxter R: Trends and characteristics of cultureconfirmed staphylococcus aureus infections in a large U.S. Integrated health care organization. J Clin Microbiol 2012, 50:1950-1957.

30. Mera RM, Suaya JA, Amrine-Madsen H, Hogea CS, Miller LA, Lu EP, Sahm DF, O'Hara P, Acosta CJ: Increasing role of Staphylococcus aureus and community-acquired methicillin-resistant Staphylococcus aureus infections in the United States: a 10-year trend of replacement and expansion. Microb Drug Resist 2011, 17:321-328.

31. Ellis Simonsen SM, van Orman ER, Hatch BE, Jones SS, Gren LH, Hegmann $K T$, Lyon JL: Cellulitis incidence in a defined population. Epidemiol Infect 2006, 134:293-299. 
32. Gordon NP: Similarity of the Adult Kaiser Permanente Membership in Northern California to the Insured and General Population in Northern California. In Statistics from the 2007 California Health Interview Survey. Oakland, CA; 2012. http://www.dor.kaiser.org/external/chis_non_kp_2007/.

33. Elliott MN, Fremont A, Morrison PA, Pantoja P, Lurie N: A New method for estimating race/ethnicity and associated disparities where administrative records lack self-reported race/ethnicity. Health Serv Res 2008.

34. Census Bureau US: A Compass for Understanding and Using American Community Survey Data: What General Data Users Need to Know. Washington, D.C.: U.S. Government Printing Office; 2008.

35. Muller LM, Gorter KJ, Hak E, Goudzwaard WL, Schellevis FG, Hoepelman Al, Rutten GE: Increased risk of common infections in patients with type 1 and type 2 diabetes mellitus. Clin Infect Dis 2005, 41:281-288.

36. Rajagopalan S: Serious infections in elderly patients with diabetes mellitus. Clin Infect Dis 2005, 40:990-996.

37. Calvet HM, Yoshikawa T: Infections in diabetes. Infect Dis Clin North Am 2001, 15:407-421. vii.

38. Frykberg RG, Zgonis T, Armstrong DG, Driver VR, Giurini JM, Kravitz SR, Landsman AS, Lavery LA, Moore JC, Schuberth JM, et al: Diabetic foot disorders. A clinical practice guideline (2006 revision). J Foot Ankle Surg 2006, 45:S1-S66.

39. Shah BR, Hux JE: Quantifying the risk of infectious diseases for people with diabetes. Diabetes Care 2003, 26:510-513.

40. Suaya JA, Eisenberg DF, Fang C, Miller LG: Skin and soft tissue infections and associated complications among commercially insured patients aged 0-64 years with and without diabetes in the U.S. PLoS One 2013, 8:e60057.

41. Karter AJ, Ferrara A, Liu JY, Moffet HH, Ackerson LM, Selby JV: Ethnic disparities in diabetic complications in an insured population. JAMA 2002, 287:2519-2527.

42. Karter AJ, Ackerson LM, Darbinian JA, D'Agostino RB Jr, Ferrara A, Liu J, Selby JV: Self-monitoring of blood glucose levels and glycemic control: the Northern California Kaiser Permanente Diabetes registry. Am J Med 2001, 111:1-9.

43. Selby JV, Ray GT, Zhang D, Colby CJ: Excess costs of medical care for patients with diabetes in a managed care population. Diabetes Care 1997, 20:1396-1402

44. Jackson LA: Evaluating diabetes mellitus as a risk factor for communityacquired infections. Clin Infect Dis 2005, 41:289-290

45. Weiss C, Kaminsky P, Boggs J, Ley C: Skin and soft-tissue infections in suburban primary care: epidemiology of methicillin-resistant Staphylococcus aureus and observations on abscess management. BMC Res Notes 2011, 4:33.

46. Jauregui LE, Babazadeh S, Seltzer E, Goldberg L, Krievins D, Frederick M, Krause D, Satilovs I, Endzinas Z, Breaux J, et al: Randomized, double-blind comparison of once-weekly dalbavancin versus twice-daily linezolid therapy for the treatment of complicated skin and skin structure infections. Clin Infect Dis 2005, 41:1407-1415.

47. Moran GJ, Krishnadasan A, Gorwitz RJ, Fosheim GE, McDougal LK, Carey RB, Talan DA: Methicillin-resistant $\mathrm{S}$. aureus infections among patients in the emergency department. N Engl J Med 2006, 355:666-674.

48. Ray GT, Suaya JA, Baxter R: Microbiology of skin and soft tissue infections in the age of community-acquired methicillin-resistant Staphylococcus aureus. Diagn Microbiol Infect Dis 2013, 76:24-30

49. Young DM, Harris HW, Charlebois ED, Chambers H, Campbell A, PerdreauRemington F, Lee C, Mankani M, Mackersie R, Schecter WP: An epidemic of methicillin-resistant Staphylococcus aureus soft tissue infections among medically underserved patients. Arch Surg 2004, 139:947-951.

50. Frazee BW, Lynn J, Charlebois ED, Lambert L, Lowery D, PerdreauRemington F: High prevalence of methicillin-resistant Staphylococcus aureus in emergency department skin and soft tissue infections. Ann Emerg Med 2005, 45:311-320.

51. Sircar KD, Bancroft E, Nguyen DM, Mascola L: Hospitalization of paediatric patients for methicillin-resistant Staphylococcus aureus skin and soft-tissue infection, 1998-2006. Epidemiol Infect 2010, 138:677-682.

52. Frei CR, Makos BR, Daniels KR, Oramasionwu CU: Emergence of community-acquired methicillin-resistant Staphylococcus aureus skin and soft tissue infections as a common cause of hospitalization in United States children. J Pediatr Surg 2010, 45:1967-1974.

53. Zilberberg MD, Chaudhari $P$, Nathanson BH, Campbell RS, Emons MF, Fiske S, Hays HD, Shorr AF: Development and validation of a bedside risk score for MRSA among patients hospitalized with complicated skin and skin structure infections. BMC Infect Dis 2012, 12:154.

54. Liu C, Graber CJ, Karr M, Diep BA, Basuino L, Schwartz BS, Enright MC, O'Hanlon SJ, Thomas JC, Perdreau-Remington F, et al: A population-based study of the incidence and molecular epidemiology of methicillinresistant Staphylococcus aureus disease in San Francisco, 2004-2005. Clin Infect Dis 2008, 46:1637-1646.

55. Sattler CA, Mason EO Jr, Kaplan SL: Prospective comparison of risk factors and demographic and clinical characteristics of community-acquired, methicillin-resistant versus methicillin-susceptible Staphylococcus aureus infection in children. Pediatr Infect Dis J 2002, 21:910-917.

56. Bar-Meir M, Tan TQ: Staphylococcus aureus skin and soft tissue infections: Can We anticipate the culture result? Clin Pediatr (Phila) 2010, 49:432-438.

doi:10.1186/1471-2334-13-252

Cite this article as: Ray et al:: Incidence, microbiology, and patient characteristics of skin and soft-tissue infections in a U.S. population: a retrospective population-based study. BMC Infectious Diseases 2013 $13: 252$

\section{Submit your next manuscript to BioMed Central and take full advantage of:}

- Convenient online submission

- Thorough peer review

- No space constraints or color figure charges

- Immediate publication on acceptance

- Inclusion in PubMed, CAS, Scopus and Google Scholar

- Research which is freely available for redistribution

Submit your manuscript at www.biomedcentral.com/submit
C) Biomed Central 